\title{
nature
}

nanotechnology

\section{Basic instincts}

\section{It is essential that governments continue to fund research that does not appear to have any obvious economic benefits, even in a field as focused on applications as nanotechnology.}

Is there a difference between nanoscience and nanotechnology? When making decisions on research papers, this journal - despite its title - does not make a distinction between the two, which is why this issue contains papers on topics as fundamental as reconfigurable DNA nanostructures (page 93) and as applied as the use of polymer nanotubules to improve the performance of commercial nanomembranes (page 112). However, as funding agencies around the world place more and more emphasis on research that is expected to have economic benefits, such differences are coming into play.

Of course, the distinction between nanoscience and nanotechnology, or between pure and applied research, is far from clear-cut: DNA-based nanomaterials may well have applications in drug delivery, for example, whereas extending the capabilities of nanomembranes requires detailed research into surface chemistry. It is important, therefore, that government funding for nanoscience and nanotechnology covers this broad spectrum, supporting and encouraging radical new ideas with no obvious applications while, at the same time, selecting specific areas that are of economic importance - in most areas of the world these tend to be in energy, health and IT (plus fish if you happen to live in Norway ${ }^{1}$ ).

Indeed, even within these more-focused programmes, there will be a need for basic research that has the potential to be useful for applications a decade or more from now. As our report on the "Emerging Technologies - Energy Harvesting Electronic Devices" session of the recent International Electronic Devices Meeting makes clear, progress in any high-tech sector needs to be made on a variety of timescales and with a range of technologies - in the case of local sources of power for sensor networks, there is scope to continue improving the performance of photovoltaic solar cells while exploring more exotic approaches such as thermoelectric and piezoelectric generators (page 71). It goes without saying that all focused programmes must also address the impact of engineered nanomaterials on human health and the environment.

In general, the pursuit of new knowledge for the sake of knowledge is the realm of governments (plus the enlightened wealthy) and universities. Taking new services and manufactured products to the market to make a profit is the province of companies, although it is important that governments ensure that a suitably educated workforce and business infrastructure are in place. However, bridging these two arenas and maintaining a balance between them will always be a challenge and, as discussed by Philip Moriarty on page 60, there are signs that this balance is skewing dangerously away from traditional academic science towards research that is focused on the needs of 'end users' in industry (which is sometimes called 'post-academic' science).

Moriarty argues that university researchers should only be involved in what the late John Ziman called "noninstrumental science". Such research is disinterested (that is, it is not associated with particular material objectives or corporate goals), non-proprietary and entirely public. Moreover, according to this school of thought, the ethos of noninstrumental science is "entirely at odds with" instrumental science (that is, research driven by the needs of end users) and it is impossible for the same researcher to be involved in both (a position that is also taken by the medical journal The Lancet ${ }^{2}$ ).

While it is possible to dispute this last point - after all, academics routinely perform teaching, research and service duties, so doing two types of research should not be beyond them, especially if they have a large group - academics are right to be wary. For instance, the UK's Science and Technology Facilities Council has just made severe cuts to its budget for basic physics research while its post-academic activities continue to grow, even though a recent report commissioned by the UK government states that research councils must increase the emphasis they place on the economic impact of their work "without sacrificing the research excellence for which the UK is rightly admired"3. Although this decision has not affected nanoscientists directly, it still shows a worrying disregard for the importance of basic research.

Moriarty also points out that there is little or no evidence to show that schemes intended to increase the economic impact of research in universities actually work, and there is anecdotal evidence that the drive to patent more university research makes collaborations between universities and companies more, rather than less, difficult. And there is ample evidence that research conducted with no application in mind can have immense economic benefits (for example, the web and the iPod - two of the defining features of the past decade - have their origins in fundamental physics research). As Leon Cooper recently put it: "When one invests in research - other than for intellectual pleasure - one invests statistically, based on history that tells us the benefits will be enormous" 4 . This is not to say that there is anything fundamentally wrong with increased commercial awareness in universities, but it should not happen at the expense of activities that are even more valuable.

\footnotetext{
References

1. www.softmachines.org/wordpress/? $\mathrm{p}=328$ (2007).

2. The Lancet 363, 2-3 (2004).

3. www.dti.gov.uk/files/file32802.pdf (2006).

4. Cooper, L. N. Nature Phys. 3, 824-825 (2007).
} 